\title{
Hepatocellular carcinoma presenting as rapidly growing sternal mass: an unusual presentation
}

\author{
Rahul S. Kulkarni, Asha S. Anand, Apurva A. Patel, Sandip A. Shah \\ Department of Medical and Paediatric Oncology, Gujarat Cancer Research Institute, Ahmedabad 380016, Gujarat, India.
}

Correspondence to: Dr. Rahul S. Kulkarni, Department of Medical and Paediatric Oncology, Gujarat Cancer Research Institute, Ahmedabad

380001, Gujarat, India. E-mail: dr.rsk08@gmail.com

\section{A B S T R A C T}

Hepatocellular carcinoma (HCC) is the most common malignant tumor of the liver. The most frequent sites of metastases are lungs, regional lymph nodes, adrenals and bones. However, an isolated sternal metastasis from HCC as an initial presentation has been rarely reported. A 45-year-old man presented with a progressively increasing mass over the anterior chest wall. On investigations, it was found to be arising from the sternum. Histopathology was suggestive of metastatic HCC, later confirmed by the presence of a $9 \mathrm{~cm} \times 7 \mathrm{~cm}$ mass in the liver on abdominal computed tomography scan and a significantly elevated serum alpha fetoprotein level. Thus, metastasis from HCC should be included in the differential diagnosis of anterior chest wall mass and rapidly growing osseous metastases at unusual sites, even in the absence of signs of liver disease.

Key words: Bony metastasis, hepatocellular carcinoma, sternal mass

\section{INTRODUCTION}

Hepatocellular carcinoma (HCC) is the most common primary malignant tumor of the liver. It commonly occurs in the 6 th and 7 th decades of life in the western countries whereas in Asia it is more common in the 4th and 5th decades. Chronic viral hepatitis, particularly hepatitis B, has been the most common etiological factor. ${ }^{[1]}$ Hematogenous extra-hepatic metastases are commonly seen in lungs, lymph nodes, kidneys, adrenals, and bones. Though bone metastasis may occur in around $10 \%$ cases with HCC, the most frequent sites are vertebrae and pelvis, rarely sternum or ribs. ${ }^{[2]}$ However, isolated sternal metastasis as the initial presentation of HCC has been rarely reported. We hereby report a case of a 45-year-old man who presented with progressively increasing anterior chest wall swelling, which was diagnosed to be sternal metastasis from incidentally diagnosed HCC.

\section{CASE REPORT}

A 45-year-old male presented to our hospital with chief complaints of progressively increasing swelling over the anterior chest wall, associated with mild pain for

\begin{tabular}{|l|l|}
\hline \multicolumn{3}{|c|}{ Access this article online } \\
\hline Quick Response Code: & Website: \\
& www.jcmtjournal.com \\
\hline & \\
\hline
\end{tabular}

2-3 months. There was no history of fever, jaundice, abdominal pain, loss of appetite and weight. Personal and family history was not significant.

On examination, there was an $8 \mathrm{~cm} \times 6 \mathrm{~cm}$ mass over the sternum, immobile and firm with no local rise of temperature. The overlying skin was tense, with dilated veins over the mass [Figure 1]. The remainder of the physical examination was unremarkable.

Routine blood investigations including hemogram and renal function tests were normal. However, liver function tests were altered, showing increased transaminases and alkaline phosphatase [Table 1]. Human immunodeficiency virus and hepatitis $\mathrm{C}$ virus were negative. However, the patient was found to be hepatitis B surface antigen-positive.

Fine needle aspiration cytology (FNAC) from the mass showed cellular smears highly suspicious of malignancy. Hence, computed tomography (CT) of thorax was done which revealed a $67 \mathrm{~mm} \times 47 \mathrm{~mm}$ expansile, osteolytic lesion with destruction and markedly enhancing soft tissues involving the manubrium, suggestive of malignant

This is an open access article distributed under the terms of the Creative Commons Attribution-NonCommercial-ShareAlike 3.0 License, which allows others to remix, tweak, and build upon the work non-commercially, as long as the author is credited and the new creations are licensed under the identical terms.

For reprints contact: service@oaepublish.com

How to cite this article: Kulkarni RS, Anand AS, Patel AA, Shah SA. Hepatocellular carcinoma presenting as rapidly growing sternal mass: an unusual presentation. J Cancer Metastasis Treat 2016;2:41-3.

Received: 21-05-2015; Accepted: 21-10-2015 
Table 1: Routine blood investigations

\begin{tabular}{lc}
\hline Investigation & Value \\
\hline Hemoglobin $(\mathrm{g} / \mathrm{dL})$ & 13 \\
Total leukocyte count $\left(\times 10^{9} / \mathrm{L}\right)$ & 9.2 \\
Platelet count $\left(\times 10^{9} / \mathrm{L}\right)$ & 260 \\
Serum creatinine $(\mathrm{mg} / \mathrm{dL})$ & 0.6 \\
Blood urea level $(\mathrm{mg} / \mathrm{dL})$ & 22 \\
Serum bilirubin $(\mathrm{mg} / \mathrm{dL})$ & 1.0 \\
SGOT $(\mathrm{mg} / \mathrm{dL})$ & 125 \\
SGPT $(\mathrm{mg} / \mathrm{dL})$ & 168 \\
Alkaline phosphatase $(\mathrm{U})$ & 360 \\
HIV & Negative \\
HBsAg & Positive \\
HCV & Negative \\
Serum AFP $(\mathrm{ng} / \mathrm{dL})$ & 34,300 \\
\hline
\end{tabular}

SGOT: serum glutamic-oxaloacetic transaminase; SGPT: serum glutamic pyruvic transaminase; HCV: hepatitis $\mathrm{C}$ virus; HIV: human immunodeficiency virus; AFP: alpha fetoprotein; HBsAg: hepatitis B surface antigen

infiltration. Both lung fields were clear, and there was no mediastinal adenopathy. Trucut biopsy showed moderate to large-sized polygonal cells with abundant eosinophilic cytoplasm and pleomorphic nuclei with a few cells showing characteristic inclusion bodies suggestive of metastatic carcinoma likely from an HCC [Figure 2].

Further, CT scan of the abdomen revealed a $9 \mathrm{~cm} \times 7 \mathrm{~cm}$ heterogeneously enhancing mass in the arterial phase in segment VIII and IV of the liver with early washout in the venous phase, suggestive of HCC [Figure 3]. Serum alpha fetoprotein (AFP) was greatly elevated at $34,300 \mathrm{ng} / \mathrm{dL}$. In view of raised AFP, characteristic liver mass and biopsy of sternal mass, the diagnosis of HCC with sternal metastasis was confirmed. The patient was treated with local radiotherapy to sternal metastasis (20 Gray, divided into 10 fractions) and was started on entecavir, $0.5 \mathrm{mg}$ daily for hepatitis B and sorafenib, $400 \mathrm{mg}$ daily for HCC. One month after the start of treatment, there was a mild reduction in the size of the sternal mass. The patient is currently under follow-up.

\section{DISCUSSION}

$\mathrm{HCC}$ is the most common primary malignant tumor of the liver and is one of the most frequently occurring malignancies in Asia. The incidence exceeds 30 cases in 100,000 people per year in the East Asian region. ${ }^{[3]}$ The course of clinically apparent disease is generally very rapid, and, if untreated, most patients die within 3-6 months after diagnosis. HCC shows both intra-hepatic and extra-hepatic metastasis, with intra-hepatic metastases occurring more frequently. Extra-hepatic metastasis has been reported in $18 \%$ of cases. ${ }^{[4]}$ The mode of extrahepatic spread is generally hematogenous, less commonly via lymphatics or direct spread. The most common sites of extra-hepatic involvement are lungs, lymph nodes, adrenals, and bones. ${ }^{[4]}$ Bony metastasis has been reported in $3-10 \%$ of cases. ${ }^{[5]}$ The most common bones involved are vertebrae, pelvis, ribs, long bones, skull and, very rarely, sternum. ${ }^{[6]}$ Further, bony metastases in HCC are

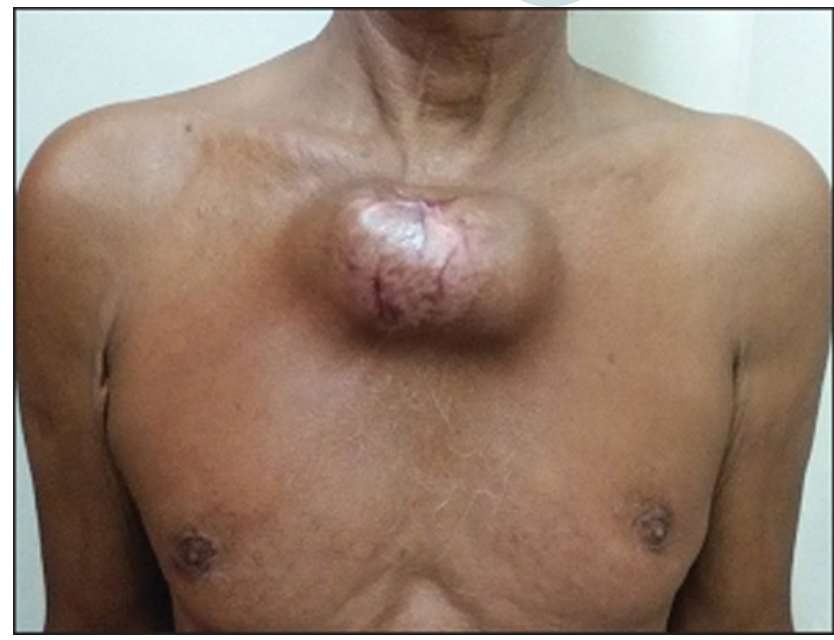

Figure 1: Prominent sternal mass on presentation

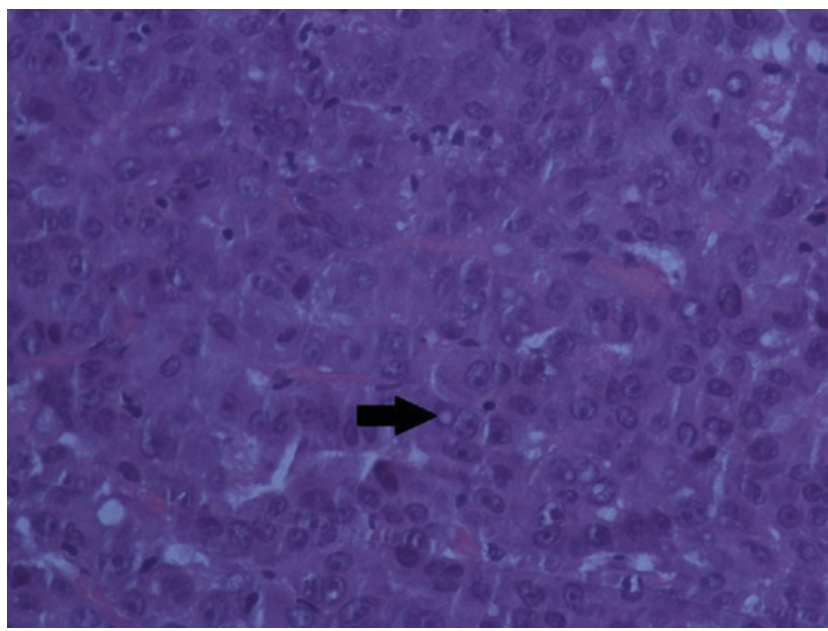

Figure 2: Hematoxylin and Eosin staining section $(\times 40)$ showing moderateto-large sized polygonal cells with abundant eosinophilic cytoplasm, pleomorphic nuclei, with few cells showing characteristic inclusion bodies (black arrow)

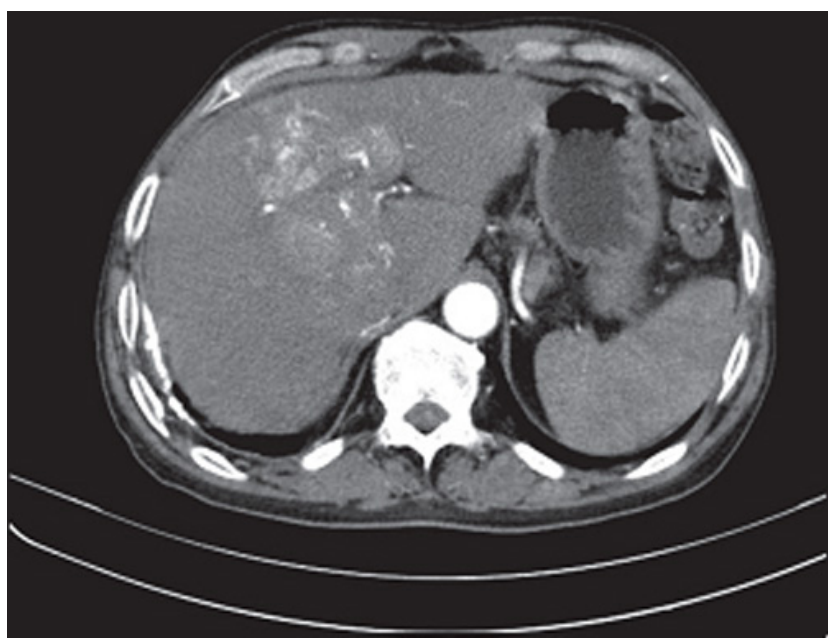

Figure 3: Computed tomography scan of abdomen showing heterogeneous enhancing mass in segment VIII and IV in liver in the arterial phase

generally multiple. An isolated bony metastasis as an initial presentation of $\mathrm{HCC}$, as in our case, is rarely seen. ${ }^{[7]}$ 
HCC bony metastases are characteristically osteolytic and hypervascular and thus may rupture spontaneously, causing hemorrhage. Chen et al. ${ }^{[7]}$ reported a case of a lifethreatening hemorrhage from sternal metastasis from HCC. Similarly, Huang et al.$^{[8]}$ have reported a case of intractable bleeding from an isolated mandibular metastasis, which was controlled by palliative radiotherapy.

Very rarely, bony metastases from an unknown primary HCC have been reported. The exact mechanism is not known, but various theories have been postulated such as metastasis from micro $\mathrm{HCC}$, which is later destroyed by the immune system, spontaneous regression of $\mathrm{HCC}$, or HCC developing in ectopic liver tissue. ${ }^{[9]}$ The etiology of HCC in our case was chronic Hepatitis B infection. In view of the raised AFP, a large liver mass and a characteristic osteolytic lesion in sternum with biopsy suggestive of HCC, the diagnosis was confirmed and an FNAC from the hepatic mass was not required.

Sorafenib is one of the first-line drugs used in the treatment of advanced metastatic HCC. Sorafenib is a tyrosine kinase inhibitor which inhibits cell growth in a dose- and time-dependent manner by altering the expression of genes involved in angiogenesis, apoptosis, and transcriptional regulation. ${ }^{[10]}$ Various other treatment modalities have been reported for bone metastasis such as chemoembolization as for a primary $\mathrm{HCC}$, systemic chemotherapy, radiotherapy or surgical resection. ${ }^{[6]}$ Unfortunately, prognosis remains poor. Median survival for HCC with bone metastasis is reported to be 6.2 months. ${ }^{[6]}$

To conclude, we here report an unusual presentation of HCC as an isolated sternal mass. A high index of suspicion is required to accurately diagnose the disease at this point. Thus, authors have recommended that metastatic HCC should be included in the list of differential diagnosis of progressively growing bony lesions at unusual sites, even in the absence of signs of liver disease.

\section{Financial support and sponsorship} Nil.

\section{Conflicts of interest}

There are no conflicts of interest.

\section{REFERENCES}

1. Anthony PP. Hepatocellular carcinoma: an overview. Histopathology 2001;39:109-18.

2. Befeler A, Bisceglie AM. Hepatocellular carcinoma: diagnosis and treatment. Gastroenterology 2002;122:1609-19.

3. Teo EK, Fock KM. Hepatocellularcarcinoma: an Asian perspective. Dig Dis 2001;19:263-8.

4. Tang ZY. Hepatocellular carcinoma-cause, treatment and metastasis. World J Gastroenterol 2001;7:445-54.

5. Si MS, Amersi F, Golish SR, Ortiz JA, Zaky J, Finklestein D, Busuttil RW, Imagawa DK. Prevalence of metastases in hepatocellular carcinoma: risk factors and impact on survival. Am Surg 2003;69:879-85.

6. Kim SU, Kim DY, Park JY, Ahn SH, Nah HJ, Chon CY, Han KH. Hepatocellular carcinoma presenting with bone metastasis: clinical characteristics and prognostic factors. J Cancer Res Clin Oncol 2008; 134:1377-84.

7. Chen CY, Chau GY, Yen SH, Hsieh YH, Chao Y, Chi KH, Li CP, Chang FY, Lee SD. Life-threatening haemorrhage from a sternal metastatic hepatocellular carcinoma. $J$ Gastroenterol Hepatol 2000;15:684-7.

8. Huang SF, Wu RC, Chang JTC, Chan SC, Liao CT, Chen IH, Yeh $\mathrm{CN}$. Intractable bleeding from solitary mandibular metastasis of hepatocellular carcinoma. World J Gastroenterol 2007;13:4526-8.

9. Qureshi SS, Shrikhande SV, Borges AM, Shukla PJ. Chest wall metastasis from unknown primary site of hepatocellular carcinoma. J Postgrad Med 2005;51:41-2.

10. Ibrahim N, Yu Y, William WR, Yang JL. Molecular targeted therapies for cancer: sorafenib monotherapy and its combination with other therapies (Review). Oncol Rep 2012;27:1303-11. 